\title{
Multicentre European study of thalamic stimulation in parkinsonian and essential tremor
}

\author{
P Limousin, J D Speelman, F Gielen, M Janssens, and study collaborators
}

Department of Clinical and Biological Neurosciences, Joseph Fourier University, Grenoble, France P Limousin

MRC HMBU, Institute of Neurology, 23 Queen Square, WC1N 3BG, London, UK

P Limousin

Department of Neurology, Academic Medical center, University of Amsterdam

J D Speelman

Medtronic Bakken Research Center, Neurological Division, PO Box 1220, $6201 \mathrm{MP}$ Maastricht, The Netherlands

F Gielen

$M$ Janssens

Correspondence to: Dr P Limousin MRC HMBU, Institute of Neurology, 23 Queen Square, London WC1N3BG, UK.

Received 23 June 1998 and in revised form

16 September 1998

Accepted 14 October 1998

\begin{abstract}
Objectives-Thalamic stimulation has been proposed to treat disabling tremor. The aims of this multicentre study were to evaluate the efficacy and the morbidity of thalamic stimulation in a large number of patients with parkinsonian or essential tremor.
\end{abstract}

Methods-One hundred and eleven patients were included in the study and 110 were implanted either unilaterally or bilaterally. Patients were evaluated with clinical scales, before and up to 12 months after surgery.

Results-Upper and lower limb tremor scores were reduced in both groups. Eighty five per cent of the electrodes satisfied the arbitrary criteria of two point reduction in rest tremor reduction in the parkinsonian tremor group and $89 \%$ for postural tremor reduction in the essential tremor group. In the parkinsonian tremor group, limb akinesia and limb rigidity scores were moderately but significantly reduced. Axial scores were unchanged. In the essential tremor group, head tremor was significantly reduced only at 3 months and voice tremor was non-significantly reduced. Activities of daily living were improved in both groups. Changes in medication were moderate. Adverse effects related to the surgery were mild and reversible.

Conclusions-Thalamic stimulation was shown to be an effective and relatively safe treatment for disabling tremor. This procedure initially applied in a very limited number of centres has been successfully used in 13 participating centres.

(F Neurol Neurosurg Psychiatry 1999;66:289-296)

Keywords: thalamic stimulation; Parkinson's disease; essential tremor

Thalamotomy for the treatment of tremor was introduced more than 40 years ago. ${ }^{1}$ The introduction of levodopa in the treatment of Parkinson's disease in 1967, and the morbidity related to thalamotomy, particularly bilateral procedures, made thalamotomy in Parkinson's disease an "outmoded therapy". ${ }^{2}$ In 1987, Benabid et al successfully treated parkinsonian patients with drug resistant tremor with chronic stimulation of the ventrointermediate nucleus of the thalamus. ${ }^{3}$ This followed the pioneer works of several neurosurgeons who applied electrical stimulation to different thalamic nuclei to treat tremor or other dyskinesias. ${ }^{4-8}$ In 1991, Benabid et al reported on 26 patients with Parkinson's disease and six patients with essential tremor and found a permanent complete or major suppression of tremor in $88 \%$ of the patients. ${ }^{9}$ Eleven patients were implanted and stimulated on both sides. The surgical morbidity was low making bilateral surgery possible. ${ }^{9}$ Other teams confirmed these findings. ${ }^{10-17}$ These preliminary studies concerned a small number of patients, or included only unilaterally stimulated patients, assessed mainly the effects on tremor, and used a global scale for the evaluation of the outcome.

In 1992 we started a multicentre European study to evaluate the efficacy and the morbidity of chronic unilateral or bilateral thalamic stimulation in a larger population of patients with severe disabling parkinsonian or essential tremor. Moreover, the effects of thalamic stimulation were evaluated for other parkinsonian symptoms and activities of daily living. The effects of unilateral stimulation were assessed on contralateral and ipsilateral symptoms. We report up to 12 month follow up of 110 patients operated on in 13 European neurosurgical centers.

\section{Patients and methods}

PATIENTS

One hundred and eleven patients (table 1), 74 with parkinsonism and 37 with essential tremor, were included between August 1992 and November 1994, according to the following criteria: (1) idiopathic Parkinson's disease or essential tremor with pharmacotherapy resistant tremor, present during the major part of the day; (2) tremor score rated 3 or 4 on the five point tremor scales $(0=$ no tremor to $4=$ very severe tremor, see assessments) for the limb intended for treatment; (3) ability to abide by the protocol and to operate the stimulator. Drugs, levodopa preparations, and dopamine agonists for parkinsonian patients, and propranolol and primidone for essential tremor patients, had to have been prescribed at maximal tolerated dosages for at least 3 months before enrollment. Two parkinsonian patients fulfilled the clinical criteria for Parkinson's disease with the exception of levodopa responsiveness. Patients were excluded from the study if they had (1) previous thalamotomy on the side of implantation; (2) significant brain atrophy or structural brain damage on CT or MRI; (3) other disorders that may interfere with the efficacy of the treatment of tremor, such as marked cognitive dysfunction, active psychiatric symptoms, and concurrent neurological or other uncontrolled medical disorders. One parkinsonian patient was withdrawn from the study before implantation because he developed 
Table 1 Patient characteristics

\begin{tabular}{lll}
\hline & $\begin{array}{l}\text { Parkinson's } \\
\text { disease }\end{array}$ & $\begin{array}{l}\text { Essential } \\
\text { tremor }\end{array}$ \\
\hline No of patients & 73 & 37 \\
Unilateral/bilateral implant (n) & $57 / 16$ & $28 / 9$ \\
Sex & $26 \mathrm{~F} / 47 \mathrm{M}$ & $13 \mathrm{~F} / 24 \mathrm{M}$ \\
Mean age at implant (y) & $61.5(10.8)$ & $63.1(12.7)$ \\
Mean duration of disease (y) & $10.0(5.6)$ & $26.6(14.5)$ \\
\hline
\end{tabular}

Values in parentheses are SD; the patient not implanted is not included in the table.

difficulty breathing early in the procedure. The study was approved by the hospital ethics committees and the patients gave written informed consent.

ASSESSMENT

Parkinsonian patients were assessed using the unified Parkinson's disease rating scale (UPDRS) version 3.0. ${ }^{18}$ All parkinsonian patients were scored in practically defined off condition (12 hours without medication). Patients with essential tremor were assessed according to the essential tremor rating scale (ETRS) ${ }^{19}$ Both scales are compound rating scales with an impairment, disability, and activities of daily living (ADL) section. Patients were scored less than 1 month preoperatively for baseline assessment and 1 week, and 3, 6, and 12 months postoperatively. Follow up scores were performed with the stimulator switched off and on. In every centre, assessments were performed by a neurologist specialised in movement disorders.

SURGICAL TECHNIQUE

The implantation and testing of the electrodes was performed under local anaesthesia. The target structure was the ventrointermediate thalamic nucleus (Vim). For the calculations of the coordinates of Vim, nine centres used positive contrast ventriculography, three in association with MRI. Three other centres used CT only and one centre MRI only. For the introduction of a test electrode a burr hole was made $2-3 \mathrm{~cm}$ lateral from the midline and just in front of the coronal suture. In addition to the imaging, two surgical centres used semimicro or microrecording to help in the location of Vim. In all centres test stimulations with high frequency $(\geqslant 100 \mathrm{~Hz})$ were performed allowing the study of tremor amplitude, diffusion of stimulation to the internal capsule, threshold for paraesthesias, and speech disturbances. Additionally some centres also applied low frequency stimulation $(2 \mathrm{~Hz}-4 \mathrm{~Hz})$ to study diffusion of the stimulation to the internal capsule. If the results were not satisfactory the test electrode was moved in a direction determined by the obtained stimulation effect. If high frequency stimulation suppressed the tremor without or with only slight transient adverse effect, the permanent quadripolar stimulation electrode (Model 3387, Medtronic, Minneapolis, USA) was implanted. Initially, all centres connected the electrode with external extension wires through the skin enabling postoperative test stimulation. A few days later if the patient obtained satisfactory results, the stimulator
(Itrel®-II, Medtronic, Minneapolis, USA) was implanted subcutaneously below the collar bone, usually under general anaesthesia, and connected with a subcutaneous extension to the electrode. During the study four centres decided to connect the stimulator immediately after implantation without the postoperative testing period, if test stimulations during the implant surgery showed good tremor suppression.

POSTOPERATIVE CARE

After implantation and at each follow up, the stimulation parameters-frequency, pulse width, and voltage - were adjusted for optimal tremor control with minimum side effects. Bipolar or monopolar stimulation could be programmed using one or a combination of the four contacts. Patients could switch the stimulator on and off using a magnet and were advised to switch the stimulator off at night. They could also use the magnet to switch the stimulation back on if it happened to be accidentally stopped by a strong environmental magnetic field. For the first 3 months after implantation the medications were kept unchanged, except in cases of unacceptable drug induced side effects.

\section{DATA ANALYSIS}

Data are presented as mean (SD) and number of values ( $\mathrm{n}$ ) at baseline, and 3 and 12 months follow up. Because of missing data we compared some results on a smaller number of patients. This number is given in the various tables. The effect of the stimulation (on stimulation versus off stimulation), the effect of the procedure (before surgery versus on stimulation), and the effect of implantation (before surgery versus off stimulation) on clinical score were studied. Activities of daily living, dyskinesias, and drug dosage at 3 and 12 months follow up were compared with baseline. The UPDRS items 32 and 33 evaluating the intensity and the duration of dyskinesias were combined and compared between baseline and 12 months in the group of patients who had a non-zero score at baseline. The same analysis was done for the UPDRS item 34 evaluating off dystonia. We calculated the number of electrodes allowing a reduction of at least two points of the upper limb, rest tremor score in the parkinsonian tremor group, and postural tremor score in the essential tremor group (maximum score four points). The different comparisons are detailed in the results section. We used the non-parametric Wilcoxon matched pairs signed rank sum test because of the number of data points per test and the expected skewed distribution of the test statistics. All $\mathrm{p}$ values are given for two sided tests. To reduce the overall risk of type I error the individual level of significance was set at $\mathrm{p}=0.005$.

\section{Results}

We present in the first part the effects of thalamic stimulation on symptomatology of parkinsonian patients, in the second part the effect on patients with essential tremor, and in 

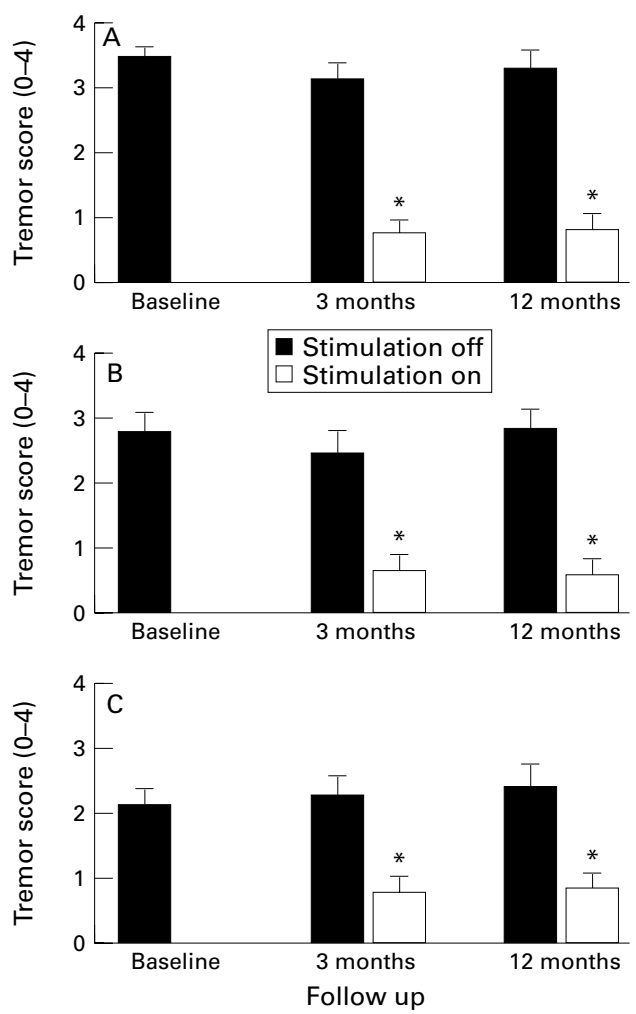

Figure 1 UPDRS subscores evaluation: upper limb rest tremor: UPDRS 20(A), upper limb posturallaction tremor:UPDRS 21 (B), and lower limb rest tremor UPDRS 20 (C) for the hemibody contralateral to surgery, in the parkinsonian tremor group. ${ }^{\star} p<0.005 v$ off stimulation.

the third part the electrical parameters of stimulation and the adverse effects for both groups of patients.

\section{PARKINSONIAN GROUP $(\mathrm{n}=73$ )}

Effect of thalamic stimulation on tremor

The effects of stimulation (on stimulation versus off stimulation), procedure (before surgery versus on stimulation), and implantation (before surgery versus off stimulation) on tremor scores were first analysed for the total population of 73 patients (fig 1). At 3 and 12 months follow up, both upper and lower limb tremor were significantly reduced by stimulation and by the procedure $(p<0.001)$. No significant effect by the implantation alone was shown. Rest tremor of the contralateral upper limb was reduced at least two points in $85 \%$ of the electrodes.

This analysis was repeated separately for the subgroup of unilaterally implanted patients to assess ipsilateral effects (table 2). The signifi- cant reduction of contralateral tremor by the stimulation and the procedure was confirmed in this subgroup at 3 and 12 months. Before surgery, patients had generally very mild tremor on the hemibody ipsilateral to surgery. At 3 months, off stimulation ipsilateral tremor was non-significantly increased in comparison with baseline and was significantly reduced by the stimulation. At 12 months, off stimulation ipsilateral tremor was back to baseline and the effect of the stimulation was not significant.

Effect of thalamic stimulation on other symptoms The procedure and stimulation significantly reduced the motor score of the UPDRS for the total population of 73 patients (table 3 ). The reduction of the score was mainly related to the effect of stimulation as off stimulation score remained the same (table 3). Symptoms other than tremor were very mild before surgery. Stimulation significantly reduced contralateral akinesia and rigidity (details of the scores in table 3) at 3 and 12 months follow up. Stimulation had the same effect on contralateral akinesia and rigidity in the group of unilaterally treated patients, whereas ipsilateral akinesia and rigidity remained unchanged (table 2). Axial symptoms, speech, postural stability, and gait were not affected by unilateral or bilateral surgery (table 4). Levodopa induced dyskinesias, evaluated by the combination of UPDRS items 32 and 33, were slightly but nonsignificantly reduced from 2.00 (SD 1.56) before surgery to 1.45 (SD 0.89) 12 months after surgery. Off dystonia, evaluated by the UPDRS item 34 was unchanged, 0.76 (SD 0.44 ) before surgery and 0.71 (SD 0.47) after surgery.

\section{Functional improvement}

Schwab and England and UPDRS II scores were improved after surgery, as a consequence of changes in motor function (table 3). Especially, item 8 (handwriting) and item 16 (invalidity related to tremor) of the UPDRS II, which are specifically influenced by tremor, were significantly reduced.

\section{Drug modifications}

Seven patients had no antiparkinsonian drug at the time of the surgery. Five of them had tried levodopa at the maximum tolerated dose and stopped because tremor was not effectively controlled. For the two other patients the neurologist in charge had decided not to try levodopa, although it is advised to try levodopa at maximum tolerated dosage before surgery.

Table 2 Effect of unilateral thalamic stimulation (total number of patients 57) on treated and non-treated hemibody symptoms, parkinsonian tremor group

\begin{tabular}{|c|c|c|c|c|c|c|}
\hline \multirow[b]{2}{*}{ Score (item of the UPDRS) } & \multirow[b]{2}{*}{ Hemibody } & \multirow[b]{2}{*}{ Baseline } & \multicolumn{2}{|l|}{3 months } & \multicolumn{2}{|l|}{12 months } \\
\hline & & & Off timulation & On stimulation & Off stimulation & On stimulation \\
\hline \multirow[t]{2}{*}{ Tremor (items 20 limbs +21 ) } & Treated & $8.04(2.54)[52]$ & $7.46(3.07)[50]$ & $1.73(1.88)[52]^{\star} \dagger$ & $8.12(3.18)[49]$ & $2.04(1.97)[50]^{\star} \dagger$ \\
\hline & Non-treated & $3.00(2.92)[52]$ & $3.31(3.26)[49]$ & $2.55(2.86)[52] \dagger$ & $3.00(3.18)[49]$ & $2.56(2.77)[50]$ \\
\hline \multirow[t]{2}{*}{ Rigidity (item 22 limbs) } & Treated & $1.87(1.84)[52]$ & $1.76(1.46)[51]$ & $1.19\left(1.31(52]^{\star} \dagger\right.$ & $2.04(1.77)[49]$ & $1.58(1.68)[50] \dagger$ \\
\hline & Non-treated & $1.19(1.53)[52]$ & $1.22(1.29)[51]$ & $1.10(1.32)[52]$ & $1.57(1.62)[49]$ & $1.42(1.55)[50]$ \\
\hline \multirow[t]{2}{*}{ Akinesia (items 23-26) } & Treated & $6.83(3.37)[52]$ & $7.45(3.67)[51]$ & $4.38(2.72)[52]^{\star} \dagger$ & $6.96(4.34)[49]$ & $4.52(3.15)[50]^{\star}+$ \\
\hline & Non-treated & $3.52(3.27)[52]$ & $4.45(3.56)$ [51] & $4.00(3.28)[52]$ & 4.39 (3.87) [49] & $4.20(3.65)[50]$ \\
\hline
\end{tabular}

Values are mean (SD) [No of patients].

${ }^{\star} \mathrm{p}<0.001 v$ baseline; $\mathrm{t} \mathrm{p}<0.001 v$ off stimulation. 
Table 3 Effect of thalamic stimulation on motor symptoms and activity of daily life, parkinsonian tremor group

\begin{tabular}{|c|c|c|c|c|c|}
\hline \multirow[b]{2}{*}{ Score (item of the UPDRS) } & \multirow[b]{2}{*}{ Baseline } & \multicolumn{2}{|l|}{3 months } & \multicolumn{2}{|l|}{12 months } \\
\hline & & Off stimulation & On stimulation & Off stimulation & On stimulation \\
\hline UPDRS III & $37.06(19.40)[67]$ & $37.40(19.51)[63]$ & $24.26(17.80)[66]^{\star} \dagger$ & $39.18(19.31)[60]$ & $25.72(18.10)[64]^{\star}+$ \\
\hline Contralateral rigidity (item 22 limbs) & $2.29(1.95)\{82\}$ & $1.95(2.32)\{81\}$ & $1.63(1.75)\{82\}^{\star}+$ & $2.51(1.97)\{77\}$ & $2.05(1.97)\{78\}^{\star} \dagger$ \\
\hline Contralateral akinesia (items $23-26$ ) & $7.43(3.98)\{82\}$ & $7.74(4.11)\{81\}$ & $4.98(3.87)\{82\}{ }^{\star}+$ & $7.21(4.41)\{77\}$ & $4.86(3.63)\{78\}^{\star} \dagger$ \\
\hline Hoehn and Yahr & $2.31(0.96)[68]$ & - & $2.24(0.93)[68]$ & - & $2.30(0.88)[65]$ \\
\hline Schwab and England & $72.35(20.88)[68]$ & - & $82.35(17.96)[68]^{\star}$ & - & $82.77(18.07)[65]^{\star}$ \\
\hline UPDRS II & $13.85(8.12)[67]$ & - & $8.61(6.65)[67]^{\star}$ & - & $9.24(6.52)[63]^{\star}$ \\
\hline Handwriting (item 8) & $2.39(1.25)[67]$ & - & $1.54(1.06)[67]^{\star}$ & - & $1.67(1.08)[64]^{\star}$ \\
\hline Tremor (item 16) & $3.13(1.05)[68]$ & - & $1.18(0.91)[68]^{\star}$ & - & $1.22(0.87)[65]^{\star}$ \\
\hline
\end{tabular}

Values are mean (SD) [No of patients] \{No of electrodes\}.

${ }^{\star} \mathrm{p}<0.001 v$ baseline, $\mathrm{tp}<0.001 v$ off stimulation.

Table 4 Effect of unilateral or bilateral thalamic stimulation on axial parkinsonian symptoms

\begin{tabular}{|c|c|c|c|c|c|c|}
\hline \multirow[b]{2}{*}{ Score (item of the UPDRS) } & \multirow[b]{2}{*}{ Stimulation } & \multirow[b]{2}{*}{ Baseline } & \multicolumn{2}{|l|}{3 months } & \multicolumn{2}{|l|}{12 months } \\
\hline & & & Off stimulation & On stimulation & Off stimulation & On stimulation \\
\hline \multirow[t]{2}{*}{ Speech (item 18) } & Unilateral & $0.75(0.76)[52]$ & $0.55(0.61)[51]$ & $0.62(0.72)[52]$ & $0.67(0.66)[49]$ & $0.72(0.67)[50]$ \\
\hline & Bilateral & $1.27(1.10)[15]$ & $1.53(1.13)[15]$ & $1.80(1.21)[15]$ & $1.29(1.07)[14]$ & $1.50(1.02)[14]$ \\
\hline \multirow[t]{2}{*}{ Postural stability (item 29) } & Unilateral & $0.77(0.98)[52]$ & $0.71(0.92)[51]$ & $0.73(0.84)[52]$ & $0.88(1.08)[48]$ & $0.82(1.04)[50]$ \\
\hline & Bilateral & $1.53(1.55)[15]$ & $1.67(1.40)[15]$ & $1.53(1.41)[15]$ & $1.50(0.94)[14]$ & $1.36(1.01)[14]$ \\
\hline \multirow{2}{*}{ Gait (item 30) } & Unilateral & $0.77(0.98)[52]$ & $0.80(0.89)[51]$ & $0.73(0.84)[52]$ & $0.90(1.08)[48]$ & $0.78(1.00)[50]$ \\
\hline & Bilateral & $1.67(1.18)[15]$ & $1.47(1.36)[15]$ & $1.40(1.40)[15]$ & $1.29(1.14)[14]$ & $1.29(1.14)[14]$ \\
\hline
\end{tabular}

Values are mean (SD) [No of patients]. No significant differences.

Sixty five patients were still taking levodopa at surgery. The number of patients using medications was not changed and the mean doses were non-significantly reduced 12 months after surgery (table 5).

ESSENTIAL TREMOR $(\mathrm{n}=37)$

Effect of thalamic stimulation on essential tremor The effect of stimulation (on stimulation versus off stimulation), procedure (before surgery versus on stimulation), and implantation (before surgery versus off stimulation) on contralateral tremor scores were first analysed for the total group of patients (fig 2). At 3 and 12 months follow up, the stimulation and the procedure significantly reduced postural and action tremor of the upper limb (fig 2, $\mathrm{p}<0.001)$. Lower limb tremor was moderate

Table 5 Medications relevant to study before and 12 months after surgery

\begin{tabular}{|c|c|c|c|c|}
\hline & \multicolumn{2}{|c|}{ Parkinson's disease } & \multicolumn{2}{|l|}{ Essential tremor } \\
\hline & Baseline & $\begin{array}{l}12 \text { months follow } \\
\text { up }\end{array}$ & Baseline & $\begin{array}{l}12 \text { months follow } \\
\text { up }\end{array}$ \\
\hline Levodopa & $649(522)[65]$ & $610(436)[65]$ & [2] & [0] \\
\hline Dopamine agonists & {$[33]$} & {$[28]$} & [1] & {$[0]$} \\
\hline $\begin{array}{l}\text { Anticholinergic } \\
\text { drugs }\end{array}$ & [13] & [12] & {$[0]$} & {$[0]$} \\
\hline MAO-B inhibitors & [15] & [11] & {$[0]$} & {$[0]$} \\
\hline Propranolol & [4] & [4] & $142(83)[13]$ & 49 (93) [13] \\
\hline Primidone & [3] & [0] & $413(330[9]$ & $153(264$ [9] \\
\hline
\end{tabular}

Mean dose (mg/day) (SD) [number of patients].

Table 6 Effect of thalamic stimulation on essential tremor and activity of daily living

\begin{tabular}{|c|c|c|c|c|c|c|}
\hline \multirow[b]{2}{*}{ Score (item from ETRS) } & \multirow[b]{2}{*}{ Group } & \multirow[b]{2}{*}{ Baseline } & \multicolumn{2}{|l|}{3 months } & \multicolumn{2}{|l|}{12 months } \\
\hline & & & Off stimulation & On stimulation & Off stimulation & On stimulation \\
\hline Tremor ETRS (item 1-9) & All & $19.21(8.22)[34]$ & $15.24(6.82)[33]$ & $7.88(5.17)[33]^{\star} \dagger$ & $17.21(7.33)[33]$ & $8.65(5.86)[34]^{\star} \dagger$ \\
\hline \multirow[t]{3}{*}{ Voice tremor (item 3) } & All & $0.63(0.69)[35]$ & $0.41(0.70)[34]$ & $0.31(0.53)[35]$ & $0.54(0.70)[35]$ & $0.40(0.69)[35]$ \\
\hline & Unilateral & $0.46(0.65)[26]$ & $0.48(0.77)[25]$ & $0.31(0.55)[26]$ & $0.42(0.76)[26]$ & $0.31(0.74)[26]$ \\
\hline & Bilateral & $1.11(0.60)[9]$ & $0.22(0.44)[9]$ & $0.33(0.50)[9]$ & $0.89(0.33)[9]$ & $0.67(0.50)[9]$ \\
\hline \multirow[t]{3}{*}{ Head tremor (item 4) } & All & $1.31(1.51)[35]$ & $1.14(1.22)[35]$ & $0.59(0.89)[34]^{\star}$ & $1.09(1.62)[35]$ & $0.71(1.30)[35]$ \\
\hline & Unilateral & $1.00(1.47)[26]$ & $1.08(1.26)[26]$ & $0.64(0.95)[25]$ & $1.15(1.80)[26]$ & $0.85(1.43)[26]$ \\
\hline & Bilateral & $2.22(1.30)[9]$ & $1.33(1.12)[9]$ & $0.44(0.73)[9] \ddagger$ & $0.89(0.93)[9]$ & $0.33(0.71)[9] \neq$ \\
\hline ADL ETRS (item 15-21) & All & $14.88(4.28)[32]$ & $15.27(6.59)[26]$ & $3.90(4.64)[30] * \dagger$ & $14.92(6.72)[24]$ & $2.93(3.39)[28] \star \dagger$ \\
\hline Hand function (item 10-14) & All & $25.43(7.39)[35]$ & $22.68(8.43)[34]$ & $13.50(7.60)[34]{ }^{\star}+$ & $25.21(7.20)[34]$ & $14.26(6.49)[34]^{\star}+$ \\
\hline
\end{tabular}

Values are mean (SD) [number of patients].

${ }^{\star} \mathrm{p}<0.001 v$ baseline; $\dagger \mathrm{p}<0.001 v$ off stimulation; $\neq \mathrm{p}<0.005 v$ unilateral. before surgery, and was significantly reduced by the procedure $(p<0.001)$. The effect of the up only $(\mathrm{p}<0.001)$. A probable persisting microthalamotomy effect decreased tremor even with the stimulator off at 3 months postsurgery. Postural tremor of the contralateral upper limb was reduced by at least two points in $89 \%$ of the electrodes. Head and voice tremor were both very mild before surgery (table 6). Head tremor was significantly improved by stimulation at the 3 month follow up only. Bilateral stimulation was more effective on head tremor than unilateral stimulation (table 6). Voice tremor was not significantly reduced after surgery and there was no difference between unilateral and bilateral surgery (table 6). The group of patients with unilateral stimulation was analysed separately to evaluate ipsilateral tremor. Stimulation and the procedure significantly reduced contralateral but not ipsilateral tremor (table 7).

\section{Activities of daily living}

The procedure improved items $10-14$ of the ETRS which evaluate hand function such as drawing, writing, and pouring and items 15-21 of the ETRS which evaluate activities of daily living (table 6). stimulation was significant at 12 months follow 

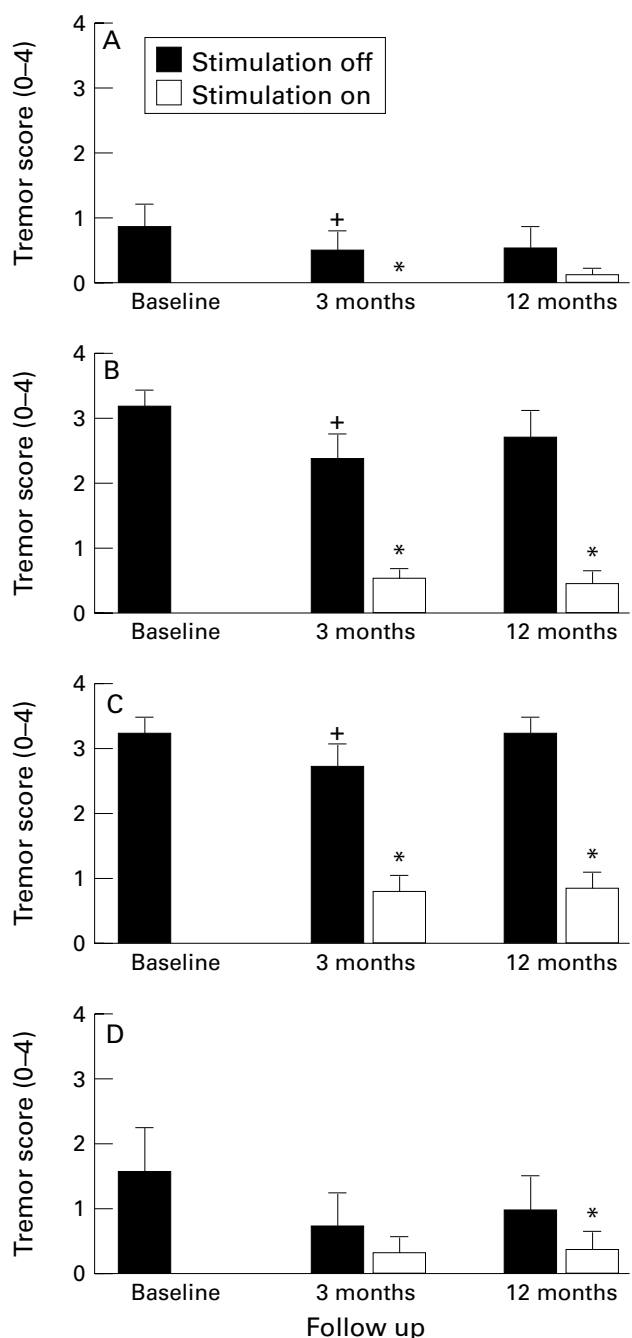

Figure 2 ETRS subscores evaluation: upper limb rest tremor: (ETRS 5 or 6) (A), upper limb postural tremor: (ETRS 5 or 6) (B), upper limb action/intention tremor: (ETRS 5 or 6) (C), and lower limb rest/postural/action tremor (ETRS 8 or 9) (D) for the hemibody contralateral to surgery, in the essential tremor group. $+p<0.005 \mathrm{v}$ baseline; ${ }^{\star} p<0.005 v$ stimulation.

Drugs

Nineteen patients had no antitremor drugs at the time of surgery. The drugs most often used were propranolol and primidone. The number of patients using medications was not changed. The mean doses of propranolol and primidone were reduced 12 months after surgery, but this difference was not significant (table 5).

ADVERSE EFFECTS

One hundred and eleven patients were enrolled in the study; 110 were implanted. One patient developed difficulties breathing in the operat- ing theatre at the time of skin incision; therefore, this patient was not implanted. Four patients had major adverse effects unrelated to surgery or stimulation. Three patients died from causes unrelated to surgery or stimulation, and one patient had a stroke in the contralateral hemisphere 3 months after surgery. He lay on the floor for a prolonged period and developed a skin erosion over the connector. Two patients had subdural haematomas, which resorbed without intervention and left no sequelae. A third patient had a subdural and a thalamic haematoma inducing transient left hemibody neglect which resolved without sequelae. Two patients had an infection of the system. The equipment was temporarily explanted and the patients treated with antibiotics. Two other patients developed subcutaneous haematomas which were evacuated. The electrode was replaced because of unsatisfactory results in five patients. This replacement resulted in a good efficacy in all patients. A transient attentional and cognitive deficit has been described in one patient. Other adverse effects, dysarthria (seven patients: five unilateral stimulation and two bilateral stimulation), disequilibrium (three patients: all bilateral stimulation), dystonia (one patient), were mild, related to the stimulation, and reversible with the change of electrical parameters. Some patients complained additionally of local pain at the implantation site of the pulse generator.

ELECTRICAL PARAMETERS AND CONTACTS

Electrical parameters used for parkinsonian tremor and essential tremor were in the same range (table 8). In both groups voltage was slightly but significantly, increased over 1 year and changes in pulse width and frequency were small. Frequencies over $130 \mathrm{~Hz}$ were usually used. Most patients were stimulated at $130 \mathrm{~Hz}$ at implant and $185 \mathrm{~Hz}$ at 12 months. Monopolar stimulation (one contact negative, the case of the pulse generator positive) was used in most patients. Bipolar stimulation (at least one contact negative and one contact positive) was used when tremor reduction was obtained, with less adverse effects than monopolar stimulation. The stimulated contact was changed over time. Contact 0 (distal) or 1 was usually placed at the optimal area determined during surgery. These deepest contacts were more often used. At 12 months, stimulation was stopped at night in 48 electrodes (out of 79) in the parkinsonian tremor group and 35 electrodes (out of 44) in the essential tremor group.

Table 7 Effect of unilateral thalamic stimulation on treated and non-treated hemibody, in the essential tremor group

\begin{tabular}{|c|c|c|c|c|c|c|}
\hline \multirow[b]{2}{*}{ Score (item from ETRS) } & \multirow[b]{2}{*}{ Hemibody } & \multirow[b]{2}{*}{ Baseline } & \multicolumn{2}{|l|}{3 months } & \multicolumn{2}{|l|}{12 months } \\
\hline & & & Off stimulation & On stimulation & Off stimulation & On stimulation \\
\hline \multirow[t]{2}{*}{ Upper limb (ETRS 5-6) } & Treated & $7.27(1.91)[26]$ & $6.04(2.31)[26]$ & $1.42(1.33)[26]]_{\ddagger}$ & $6.73(2.15)[26]$ & $1.42(1.10)[26]^{\star} \ddagger$ \\
\hline & Non-treated & $5.69(2.81)[26]$ & $5.96(3.10)[26]$ & $5.50(3.11)[26]$ & $6.32(3.29)[25]$ & $5.92(2.82)[26]$ \\
\hline \multirow[t]{2}{*}{ Lower limb (ETRS 8-9) } & Treated & $1.81(2.64)[26]$ & $1.15(2.03)[26]$ & $0.50(1.03)[26] \dagger$ & $1.27(2.15)[26]$ & $0.46(1.10)[26] \rrbracket$ \\
\hline & Non-treated & $1.08(2.13)[26]$ & $0.85(1.19)[26]$ & $0.73(1.22)[26]$ & $1.23(2.03)[26]$ & $0.92(1.49)[26]$ \\
\hline
\end{tabular}

Values are mean (SD) [No of patients].

${ }^{\star} \mathrm{p}<0.001,+\mathrm{p}<0.005 v$ baseline; $\neq \mathrm{p}<0.001 ; \S \mathrm{p}<0.005 v$ off stimulation. 
Table 8 Electrical parameters of stimulation at implant, 3 month, and 12 month follow up

\begin{tabular}{|c|c|c|c|c|c|c|}
\hline & \multicolumn{3}{|l|}{ Parkinson's disease } & \multicolumn{3}{|l|}{ Essential tremor } \\
\hline & Implant & 3 months & 12 months & Implant & 3 months & 12 months \\
\hline Voltage (V) & $1.97(0.87)[85]$ & $2.34(0.93)[83]^{\star}$ & $2.51(0.93)[78]^{\star}$ & $1.93(0.79)[45]$ & $2.17(0.81)[44]^{\star}$ & $2.40(0.77)[44]^{\star}$ \\
\hline Pulse width) (s) & $89.65(45.44)[86]$ & $88.92(45.05)[83]$ & $81.92(30.45)[78]$ & $92.00(44.04)[45]$ & $92.73(39.26)[44]$ & $83.86(31.42)[44]$ \\
\hline Rate $(\mathrm{Hz})$ & $147.50(24.38)[86]$ & $156.45(25.16)[83]$ & $162.95(28.42)[78]$ & $151.56(23.74)[45]$ & $156.36(24.72)[44]$ & $163.64(24.42)[44]$ \\
\hline Monopolar & [66] & [69] & [71] & [38] & [39] & [39] \\
\hline Bipolar & [23] & [15] & [7] & [8] & [5] & {$[5]$} \\
\hline \multicolumn{7}{|l|}{ Contacts: $†$} \\
\hline $0-/+/$ off & $47 / 0 / 42$ & $42 / 2 / 40$ & $32 / 2 / 44$ & $21 / 1 / 24$ & $17 / 2 / 26$ & $18 / 2 / 24$ \\
\hline $1-/+/$ off & $31 / 12 / 46$ & $35 / 9 / 40$ & $42 / 3 / 33$ & $21 / 7 / 18$ & $21 / 3 / 20$ & $21 / 3 / 20$ \\
\hline $2-/+/$ off & $15 / 7 / 67$ & $14 / 1 / 29$ & $21 / 1 / 56$ & $11 / 0 / 35$ & $18 / 3 / 63$ & $17 / 0 / 27$ \\
\hline $3-/+/$ off & $8 / 3 / 78$ & $4 / 2 / 78$ & $4 / 1 / 73$ & $1 / 1 / 44$ & $2 / 0 / 42$ & $2 / 0 / 42$ \\
\hline
\end{tabular}

Values are mean (SD) [No of electrodes]. †For each contact (0 to 3), No of patients who have a setting with a negative (-) polarity/a positive (+) polarity/contact off (off).

${ }^{\star} \mathrm{p}<0.001 v$ implant.

\section{Discussion \\ TREMOR}

This study confirms the clear effect of thalamic stimulation on parkinsonian and essential tremor. Upper and lower limb tremor were improved in a large group of patients operated in different centres. Eighty five per cent (parkinsonian tremor) to $89 \%$ (essential tremor) of the electrodes gave a reduction of upper limb tremor amplitude satisfying the arbitrary criteria of two point reduction. Unilateral stimulation mainly improved contralateral tremor; therefore, patients with severe bilateral tremor usually needed a bilateral procedure.

In the essential tremor group, head and voice tremor were non-significantly improved after 1 year follow up. These symptoms were very mild before surgery and were not an indication for operation. Therefore the differences are small and might explain why they are not significant. A recent study shows that voice tremor can be improved. ${ }^{20}$ Head tremor was more improved after a bilateral procedure than after a unilateral one, probably because of the bilateral innervation of neck muscles.

The beneficial effect of the stimulation on limb tremor was maintained over 1 year but the voltage had to be increased. The necessity to increase the voltage could be related to some tolerance effect, or the decrease of the lesion effect of implantation. A previous study in a smaller group of patients has shown that the benefit remains in most patients followed up to 7 years, although a few patients can develop tolerance. ${ }^{21}$ Tremor reduction improved motor function both for parkinsonian patients and patients with essential tremor. This result is in agreement with a recent study on the effect of thalamic stimulation on disability in a small group of patients. ${ }^{17}$

OTHER PARKINSONIAN SYMPTOMS

An improvement in limb akinesia and rigidity was seen in the parkinsonian group. Akinesia and rigidity are difficult to assess with severe tremor which could have masked their appearance before surgery. However, the decrease in arm akinesia reflects an improvement in hand function whatever the mechanism. A formal assessment of the effects of thalamic stimulation on akinesia and rigidity has not been done before. Thalamotomy improved rigidity but did not improve akinesia in the long term. ${ }^{22}$
Thalamic stimulation had no effect on axial akinesia, as already shown by a study of gait. ${ }^{23}$ Therefore, patients disabled only by tremor may be operated on in this target. Other patients should be offered another procedure such as pallidal or subthalamic nucleus surgery which can improve tremor and other symptoms. ${ }^{24-28}$ Dyskinesias were slightly but non-significantly decreased after surgery in our study. Other groups also did not find a clear antidyskinetic effect. ${ }^{21}$ Capparos-Lefebvre et al found a significant decrease in dyskinesias related to thalamic stimulation which could be related to a more medial location of the electrode. ${ }^{129}$ Our protocol did not include a dyskinesia scale; evaluation of dyskinesias was based on questions to the patient (UPDRS items 32 to 34). Therefore, the effect of thalamic stimulation on dyskinesias needs to be studied with a more specific protocol.

\section{ADVERSE EFFECTS}

Thalamic implantation had a low rate of severe adverse effects even in bilateral procedures. Most adverse effects were mild and reversible. Thalamotomies are very effective on tremor, but the morbidity, including speech disturbances, disequilibrium, and cognitive dysfunction, limits the number of indications, particularly in cases of bilateral symptoms. Cognitive functions were not evaluated formally during this study but one patient only declared having some transient cognitive impairment after surgery. Previous studies have shown the absence of major cognitive change. ${ }^{30}{ }^{31}$ The incidence of haemorrhage was very low in our study; $4 \%$ of the patients had an extracerebral haemorrhage without sequela and one patient had a small intracerebral haemorrhage. An 8\% risk of haemorrhage was found in a previous thalamic stimulation series of which one quarter were asymptomatic. ${ }^{21}$ In our study, MRI control was performed only in a few centres. Therefore, we could have missed some asymptomatic bleeds. The risks of persistent adverse effects during thalamotomy and thalamic stimulation are difficult to compare as there is no published comparative study, but one is now in progress in The Netherlands. ${ }^{32}$ After thalamotomy this risk varies for transient or mild adverse events between $25 \%$ and $30 \%$ of the operations, and for significant sequela between $2 \%$ and $7 \%$ for unilateral surgery and after bilateral thalamotomy adverse events up to $60 \%$ were 
reported. $^{22}$ 33-39 Five electrodes had to be replaced because they had moved or results were unsatisfactory. This underlines the necessity of a control of the final location of the electrode with meticulous test stimulation and careful fixation of the electrode to the skull. Impairment of speech and stability were mild and always reversible when the stimulation voltage was decreased. These effects were seen more often and were more severe after thalamotomy and could be permanent, especially after bilateral thalamotomy. ${ }^{22}$

\section{PARAMETERS OF STIMULATION}

Voltage was slightly increased over time. Most patients were able to stop the stimulation at night. This is more difficult with parkinsonian tremor than with essential tremor because of the rest component. The quadripolar electrode was useful as the stimulated contacts were changed over time. The implantation of the electrode induced a transient lesion-like effect on upper limb tremor. This effect had disappeared at the 3 month follow up. Because of this transient effect, electrical parameters often needed adjustment in the first months after surgery.

\section{MEDICATIONS}

Antiparkinsonian drugs were unchanged after surgery, probably because some parkinsonian symptoms are not controlled by thalamic stimulation. Also, levodopa has an additive effect to stimulation to control tremor in some patients. Previous studies found that only one third of the patients can decrease drug dosage. ${ }^{90}$ Propranolol and primidone dosages were decreased in the essential tremor group but the difference was not significant, probably because of the few patients and the large SD.

In conclusion, in an open, prospective multicentre study the beneficial effects of chronic thalamic stimulation for parkinsonian and essential tremor were confirmed. Moreover, a slight but significant improvement was found for the other parkinsonian symptoms rigidity and akinesia. In addition, the UPDRS functional score improved significantly. This study was open which might introduce some bias in the assessment; to reduce this risk the assessment was performed independently of the surgical team. Long term comparative studies are needed to determine the respective indication of thalamic, subthalamic nucleus, and pallidal surgery in the treatment of parkinsonian tremor. Bilateral implantation of a stimulation electrode is possible because of the few transient adverse events.

PL and JDS evaluated patients in their group and were responsible for writing the paper. FG and MJ were responsible for data management and analysis. Study group collaborators included a neurosurgeon and a neurologist at each centre, they evaluated and implanted the patients and they provided comments on the paper. Members of the group are: A Benabid, P Pollak (Grenoble); F Alesch, M Pinter (Vienna); S Rehncrona, R Ekberg (Lund); L Augustinsson, B Johnels (Gothenburg); B Meyerson, O Sydow (Stockholm); J N'Guyen, C Geny (Paris); D Bosch (Amsterdam); M Hariz, F Johansson (Umea); M Deruytter, P Bourgeois (Roeselare); J Lemaire, F Durif (Clermont Ferrand); T Varma, R Roberts (Dundee), D Thomas, N Quinn (London), T Varma, R Roberts (Dundee), D Thomas, N Quinn (London), apolis, USA, for financial support and Mr Keith Mullett for his comments on the manuscript.
1 Hassler R, Riechert T. Indikationen und lokalisationsmethode der gezielten hirnoperationen. Nervenartz 1954:25:441-7.

2 Hurtig HI, Stern MB. Thalamotomy for Parkinson's disease [letter]. F Neurosurg 1985;62:163-5.

3 Benabid AL, Pollak P, Louveau A, et al. Combined (thalamotomy and stimulation) stereotactic surgery of the VIM thalamic nucleus for bilateral Parkinson disease. Appl Neurophysiol 1987;50:344-6.

4 Bechtereva NP, Kambarova DK, Smirnov MV, et al. Using the brain's latent abilities for therapy: chronic intracerebral electrical stimulation. In: Sweet WH, Obrador S, MartinRodriguez JG, eds. Neurosurgical treatment in psychiatry, pain and epilepsy. Baltimore: University Park Press, 1975: 581-613.

5 Brice J, McLellan. Suppression of intention tremor by contingent deep brain stimulation. Lancet 1980;i:1221-2.

6 Mazars G, Merienne L, Cioloca C. Control of dyskinesias due to sensory deafferentation by means of thalamic stimudue to sensory deafferentation by means of tha
lation. Acta Neurochir Suppl 1980;30:239-43.

7 Andy OJ. Thalamic stimulation for control of movement disorders. Appl Neurophysiol 1983;46:107-11.

8 Siegfried J. Effet de la stimulation du noyau sensitif du thalamus sur les dyskinésies et la spasticité. Rev Neurol 1986;142:380-3.

9 Benabid AL, Pollak P, Gervason C, et al. Long-term suppression of tremor by chronic stimulation of the ventra intermediate thalamic nucleus. Lancet 1991;337:403-6.

10 Blond S, Siegfried J. Thalamic stimulation for the treatment of tremor and other movement disorders. Acta Neurochir 1991;52:109-11.

11 Blond S, Caparros Lefebvre D, Parker F, et al. Control of tremor and involuntary movement disorders by chronic stereotactic stimulation of the ventral intermediate thalamic nucleus. F Neurosurg 1992;77:62-8.

12 Caparros Lefebvre D, Blond S, Vermersch P, et al. Chronic thalamic stimulation improves tremor and levodopa thalamic stimulation improves tremor and levodopa surg Psychiatry 1993;56:268-73.

13 Speelman JD, Bosch DA. Continuous electrical stimulation of the thalamus in the treatment of drug resistant tremor. Ned Tijdschr Geneeskd 1995;138:926-30.

14 Alesch F, Pinter MM, Helscher RJ, et al. Stimulation of the ventral intermediate thalamic nucleus in tremor dominated Parkinson's disease and essential tremor. Acta Neurochir 1995; 136:75-81.

15 Koller W, Hristova A. Efficacy and safety of stereotaxic surgical treatment of tremor disorders. European fournal of Neurology 1996;3:507-14.

16 Koller W, Pahwa R, Busenbark K, et al. High-frequency unilateral thalamic stimulation in the treatment of essential and parkinsonian tremor. Ann Neurol 1997;42:292-9.

17 Hariz GM, Bergenheim AT, Hariz MI, et al. Assessment of ability/disability in patients treated with chronic thalamic ability/disability in patients treated with chronic that

18 Fahn S, Elton R. Unified Parkinson's disease rating scale. In: Fahn S, Marsden CD, Calne D, et al, eds. Recent developments in Parkinson's disease. Vol II. Florham Park: MacMillan Healthcare Information, 1987:153-63

9 Fahn S, Tolosa E, Marin C. Clinical rating scale for tremor. In: Jankovic J, Tolosa E. eds. Parkinson's disease and movement disorders. Munich, Urban, and Schwarzenberg, 1988:225-34.

20 Carpenter MA, Pahwa R, Miyawaki KL, et al. Reduction of voice tremor under thalamic stimulation. Neurology 1998; 50:796-8.

21 Pollak P, Benabid AL, Limousin P, et al. Chronic intracerebral stimulation in Parkinson's disease. Adv Neurol 1997;74:213-20.

22 Speelman JD. Parkinson's disease and stereotaxic neurosurgery. Amsterdam: Thesis, 1991.

23 Defebvre L, Blatt JL, Blond S, et al. Effect of thalamic stimulation on gait in Parkinson disease. Arch Neurol 1996,53:898-903.

24 Laitinen LV, Bergenheim AT, Hariz MI. Leksell's posteroventral pallidotomy in the treatment of Parkinson's disease. f Neurosurg 1992;76:53-61.

25 Lang AE, Lozano AM, Montgomery E, et al. Posteroventral medial pallidotomy in advanced Parkinson's disease. $N$ Engl f Med 1997;337:1036-42.

26 Siegfried J, Lippitz B. Bilateral chronic electrostimulation of ventroposterolateral pallidum: a new therapeutic approach for alleviating all parkinsonian symptoms. Neurosurgery 1994;35:1126-9.

27 Limousin P, Pollak P, Benazzouz A, et al. Effect of parkinsonian signs and symptoms of bilateral subthalamic nucleus nian signs and symptoms of bilater

28 Krack P, Pollak P, Limousin P, et al. Stimulation of the subthalamic nucleus alleviates tremor in Parkinson's disease. Lancet 1997;350:1675.

29 Benabid AL, Blond S, Pollak P, et al. Electrical neuroinhibition of CMPf is effective on tremor and L-dopa induced dyskinesias in Parkinson's disease. Neurology 1997;48:A357.

30 Caparros Lefebvre D, Blond S, Pecheux $\mathrm{N}$, et al. Neuropsychological evaluation before and after thalamic stimulation in nine patients with Parkinson disease. Rev Neurol 1992;148:117-22.

31 Troster AI, Fields JA, Wilkinson SB, et al. Neuropsychological functioning before and after unilateral thalamic stimulating electrode implantation in Parkinson's disease. Neurosurgical Focus 1997;2:1-6.

32 Schuurman PR, Speelman JD, Bosch DA. Thalamic stimulation versus thalamotomy in a prospective randomized trial. In: Abstracts of oral presentations, 12th Meeting of the 
World Society for Stereotactic and Functional Neurosurgery, Lyon: WSSFN, 1997:38. Present indications and value. In: Rinne UK, Klinger $M$, Stamm G, eds. Parkinson's disease: current progress, problems, and management. Amsterdam: Elsevier, 1980:369-76.

34 Tasker RR. Siqueira J, Hawrylyshyn P, et al. What happened to VIM-thalamotomy for Parkinson's disease? Appl Neurophysiol 1983;46:68-83.

35 Gildenberg PL. The present role of stereotactic surgery in the management of Parkinson's disease. Adv Neurol 1984;40:447-52.

36 Nagaseki Y, Shibazaki T, Hirai T, et al. Long-term follow-up results of selective VIM-thalamotomy. $\mathcal{F}$ Neurosurg $1986 ; \mathbf{6 5}$ :
296-302.

37 Narabayashi H. Stereotaxic VIM thalamotomy for treatment of tremor. Eur Neurol 1989;29:29-32.

38 Fox MW, Ahlskog JE, Kelly PJ. Stereotactic ventrolateralis thalamotomy for medically refractory tremor in postlevodopa era Parkinson's disease patients [see comments]. f Neurosurg 1991;75:723-30.

39 Jankovic J, Cardoso F, Grossman RG, et al. Outcome after stereotactic thalamotomy for parkinsonian, essential, and other types of tremor. Neurosurgery 1995;37:680-6.

40 Benabid AL, Pollak P, Seigneuret E, et al. Chronic VIM thalamic stimulation in Parkinson's disease, essential tremor and extra-pyramidal dyskinesias. Acta Neurochir 1993;58: $39-44$

\section{Fournal of Neurology Neurosurgery and Psychiatry - http://www.jnnp.com}

Visitors to the world wide web can now access the fournal of Neurology Neurosurgery and Psychiatry either through the BMJ Publishing Group's home page (http://www.bmjpg.com) or directly by using its individual URL (http://www.jnnp.com). There they will find the following:

- Current contents list for the journal

- Contents lists of previous issues

- Members of the editorial board

- Subscribers' information

- Instructions for authors

- Details of reprint services.

A hotlink gives access to:

- BMJ Publishing Group home page

- British Medical Association web site

- Online books catalogue

- BMJ Publishing Group books.

The web site is at a preliminary stage and there are plans to develop it into a more sophisticated site. Suggestions from visitors about features they would like to see are welcomed. They can be left via the opening page of the BMJ Publishing Group site or, alternatively, via the journal page, through "about this site". 